$\begin{gathered}\text { Bioeduca: Journal of Biology Education } \\ \text { http://journal.walisongo.ac.id/index.php/bioeduca } \\ \text { ISSN 2714-8009 (print), 2715-7490 (online) }\end{gathered}$
Bolume 2, Nomor 1, Tahun 2020
Hal. 9-15

\title{
Komparasi Motivasi Belajar Siswa Materi Perubahan Lingkungan dan Daur Ulang Limbah Melalui Metode Everyone Is Teacher Here dan Guided Note Taking
}

\author{
Uli Nur Safitri ${ }^{1 *}$,Nur Khoiri ${ }^{2}$, Anif Rizqianti Hariz ${ }^{3}$ \\ ${ }^{1,2,3}$ Pendidikan Biologi, Univeristas Islam Negeri Walisongo Semarang \\ *Email: Ulisafitri03@gmail.com
}

\begin{tabular}{|c|c|}
\hline Informasi Artikel & ABSTRAK \\
\hline $\begin{array}{l}\text { Submit: } 01-08-2019 \\
\text { Diterima: } 12-12-2019 \\
\text { Dipublikasikan: } 12-03-2020\end{array}$ & $\begin{array}{l}\text { Permasalahan yang sering terjadi di kelas adalah kurangnya } \\
\text { motivasi belajar siswa dan variasi metode pembelajaran yang } \\
\text { dipakai oleh guru dalam proses pembelajaran biologi. Tujuan } \\
\text { penelitian ini adalah menjelaskan kriteria motivasi belajar siswa } \\
\text { pada materi perubahan lingkungan dan daur ulang limbah dan } \\
\text { menganalisis perbedaan motivasi belajar siswa menggunakan } \\
\text { metode everyone is teacher here dan guided note taking pada } \\
\text { kelas X MAN } 1 \text { Semarang tahun pelajaran } 2018 / 2019 \text {. Jenis } \\
\text { penelitian yang digunakan adalah penelitian eksperimen dengan } \\
\text { desain quasi eksperimental. Hasil skor motivasi belajar melalui } \\
\text { metode everyone is teacher here yaitu } 73,97 \text { sedangkan melalui } \\
\text { metode guided note taking sebesar } 69,81 \text {. Berdasarkan analisis } \\
\text { uji t diketahui thitung sebesar } 2.3315 \text { dan tabel } 1,666 \text { sehingga } \\
\text { dapat disimpulan Ha diterima karena thitung }>\text { ttabel. } \\
\text { Kata kunci: metode pembelajaran; motivasi belajar. }\end{array}$ \\
\hline Penerbit & ABSTRACT \\
\hline $\begin{array}{l}\text { Program Studi Pendidikan } \\
\text { Biologi, Fakultas Sains dan } \\
\text { Teknologi, UIN Walisongo } \\
\text { Semarang }\end{array}$ & $\begin{array}{l}\text { Problems that often occur in class are the lack of student } \\
\text { motivation and variety of learning methods used by teachers in } \\
\text { the learning process of biology. The purpose of this study is to } \\
\text { explain criteria student motivation on environmental change and } \\
\text { waste recycling material using the analyze differences in student } \\
\text { learning motivation using the everyone is teacher here and } \\
\text { guided note taking method in class XMAN } 1 \text { Semarang in School } \\
\text { year } 2018 / 2019 \text {. This type of research is an experimental } \\
\text { research with quasi experimental design. The result of learning } \\
\text { motivation score through the the method of everyone is teacher } \\
\text { here is } 73.97 \text { while the guided note taking method is } 69.81 \text {. Based } \\
\text { on t test analysis, it is known that tount is } 2.3315 \text { and table is } 1.666 \text {. } \\
\text { so it can be conclude that Ha is accepted because } t_{\text {count }}>t_{\text {table }} \\
\text { Keywords: learning method; learning motivation. }\end{array}$ \\
\hline
\end{tabular}

Copyright (C2020, Bioeduca: Journal of Biology Education

Uli Nur Safitri et al.- Komparasi Motivasi Belajar Siswa Materi Perubahan Lingkungan dan Daur Ulang Limbah Melalui Metode Everyone is Teacher Here 


\section{PENDAHULUAN}

Pendidikan merupakan suatu proses transfer pengetahuan. Dalam dunia pendidikan, guru memiliki tugas untuk memberikan atau menyampaikan ilmu yang dimilikinya kepada siswa yang diajarnya. Untuk mendapatkan hasil yang optimal dalam pembelajaran, harus ada hubungan yang baik antara siswa dengan guru. Guru memiliki peran untuk memimpin, mengendalikan dan mengarahkan siswa. Untuk itu, diperlukan keaktifan dalam pembelajaran agar dapat tercapainya tujuan belajar.

Motivasi belajar merupakan suatu dorongan yang berasal dari dalam diri sendiri maupun dari luar yang akan mempengaruhi peserta didik dalam kegiatan belajar. Dalam setiap pembelajaran siswa terkadang tidak selalu semangat dalam belajar. Untuk itu, sebagai seorang guru haruslah mempunyai cara untuk meningkatkan semangat belajar siswa. Motivasi siswa dalam belajar ini akan berpengaruh terhadap apa yang ingin dicapai (Suprijono, 2012).

Faktor-faktor yang dapat mempengaruhi motivasi belajar siswa yaitu yang berasal dari dalam dirinya sendiri (intrinsik) dan yang berasal dari luar atau orang lain(ekstrinsik). Yang berasal dari dalam diri biasanya dilatarbelakangi oleh pemikiran siswa yang positif, bahwa pelajaran yang di pelajari sangat penting dan berguna untuk masa depan. Sedangkan motivasi ekstrinsik yaitu siswa ingin mencapai tujuan belajarnya karena ingin mendapatkan hadiah, nilai yang baik maupun pujian dari guru maupun orang lain (Djamarah,2008).

Metode Everyone is Teacher Here merupakan metode yang tepat untuk mendapatkan partisipasi kelas secara keseluruhan maupun individual. Melalui metode ini nantinya siswa diharapkan dapat mengemukakan pendapatnya dan kemudian dapat mengemukakan pendapatnya dan kemudian dapat menjelaskan materi yang akan disampaikan kepada temanya menggunakan bahasanya sendiri.

Metode Guided Note Taking merupakan metode yang memungkinkan siswa belajar lebih aktif, karena memberikan kesempatan untuk mengembangkan diri dan menjadikan perhatian terfokus terhadap konsep materi yang akan dipelajarinya sehingga dapat dikembangkan menjadi pemikiran yang lebih luas. Suprijono (2012) mengatakan bahwa metode pembelajaran lain yang dapat dikembangkan untuk membangun stock of knowledge peserta didik adalah metode catatan terbimbing (guided note taking). Metode catatan terbimbing dikembangkan agar metode ceramah yang dibawakan guru mendapat perhatian siswa.

Berdasarkan wawancara dengan guru biologi di MAN 1 Semarang lbu Sih Suhartini SPd, M.Si, dapat diketahui bahwa permasalahan yang terjadi di kelas adalah kurangnya motivasi belajar siswa dan variasi metode pembelajaran yang dipakai oleh guru dalam proses pembelajaran biologi. Guru masih menggunakan metode ceramah interaktif sehingga saat pembelajaran siswa kurang termotivasi belajar pada materi biologi.

Berdasarkan latar belakang tersebut, dapat diketahui tujuan penelitian yaitu Menjelaskan kriteria motivasi belajar siswa pada materi perubahan lingkungan dan daur ulang limbah dengan menggunakan metode everyone is teacher here kelas $\mathrm{X}$ MAN 1 Semarang tahun pelajaran 2018/2019, Menjelaskan kriteria motivasi belajar 
siswa pada materi perubahan lingkungan dan daur ulang limbah dengan menggunakan metode guided note taking kelas X MAN 1 Semarang tahun pelajaran 2018/2019 dan Menganalisis kriteria perbedaan motivasi belajar siswa pada materi perubahan lingkungan dan daur ulang limbah dengan menggunakan metode everyone is teacher here dan guided note taking kelas X MAN 1 Semarang tahun pelajaran $2018 / 2019$.

\section{METODE PENELITIAN}

Penelitian ini dilakukan di kelas X MIPA MAN 1 Semarang. Jenis penelitian yang digunakan adalah penelitian eksperimen dengan desain quasi eksperimental. Penelitian ini bertipe, the nonequivalent posttest- only control design dimana pada desain ini terdapat 2 kelompok, kelompok pertama diberi perlakuan berbeda dengan kelompok kedua, kemudian dua kelompok tersebut diberi posttest (Lestari dan Yudhanegara, 2015).

Teknik pengambilan sampel dalam penelitian ini yaitu sampling purposive, dimana penentun sampel dilakukan dengan pertimbangan tertentu sehingga didapatkan 2 kelas penelitian sebagai sampel penelitian (Sugiyono,2016). Kelas eksperimen I yaitu kelas X MIPA 4 dan eksperimen II kelas X MIPA 5.

Teknik pengumpulan data menggunakan kuesioner (angket) dan dokumentasi. Teknik pengumpulan data menggunakan angket dilakukan dengan cara memberikan daftar pertanyaan kepada responden yang berhubungan dengan penelitian. Kriteria motivasi belajar siswa sebagai berikut.

Tabel 1. Kriteria motivasi belajar siswa

\begin{tabular}{cl}
\hline Skor & \multicolumn{1}{c}{ Kriteria } \\
\hline $75 \%-100 \%$ & motivasi belajar siswa baik \\
\hline $50 \%-74,9 \%$ & motivasi belajar siswa cukup baik \\
\hline $25 \%-49,9 \%$ & motivasi belajar siswa kurang baik \\
\hline $0 \%-24,9 \%$ & motivasi belajar siswa sangat kurang \\
\hline
\end{tabular}

\section{HASIL PENELITIAN DAN PEMBAHASAN}

Berdasarkan perhitungan data post-test yang diperoleh dari angket motivasi belajar siswa, dapat diketahui bahwa kelas eksperimen I yang disampaikan melalui metode everyone is teacher here yaitu kelas X MIPA 4 memiliki skor yang lebih tinggi dibanding kelas eksperimen II yaitu kelas X MIPA 5. Kelompok kelas eksperimen I yang disampaikan melalui metode guded note taking berjumlah 38 siswa memiliki skor rata-rata sebesar 73,97 . Sedangkan kelas eksperimen II yang berjumlah 37 siswa memiliki skor rata-rata 69,81 .

Berdasarkan gambar 1 dan 2, dapat diketahui bahwa siswa yang diajar menggunakan metode everyone is teacher here memiliki persentase sebesar 88,06\% dan dapat dikategorikan memiliki motivasi dalam kriteria baik sedangkan yang diajar menggunakan metode guided note taking memiliki persentase sebesar $83,10 \%$ dikategorikan dalam motivasi belajar baik. 


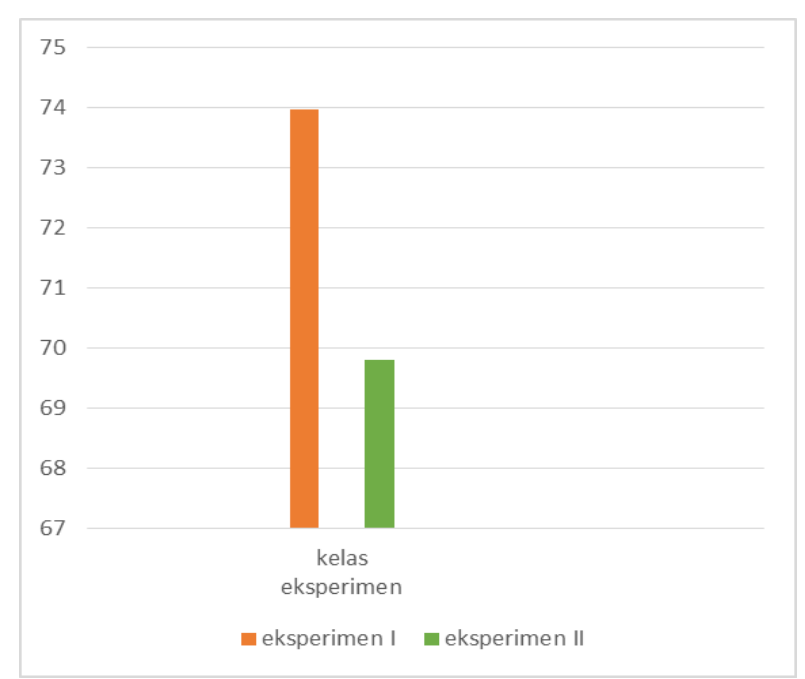

Gambar 1. Grafik perbandingan rata-rata skor motivasi belajar kelas eksperimen I dan II

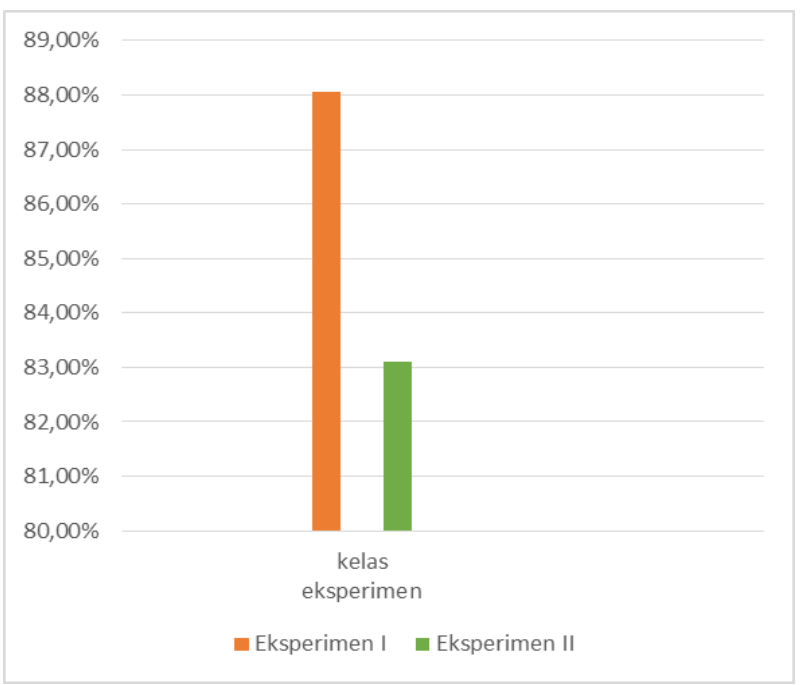

Gambar 2. Grafik persentase rata-rata motivasi belajar kelas eksperimen I dan II

Hasil uji $\mathrm{t}$ menunjukkan bahwa pada taraf signifkansi $5 \%$ dengan $\mathrm{dk}=73$ didapatkan thitung sebesar 2,3315 dan tabel sebesar 1,666. Sehingga dapat disimpulkan bahwa thitung $>t_{\text {tabel }}$ maka Ho ditolak dan Ha diterima. Artinya motivasi belajar siswa materi perubahan lingkungan dan daur ulang limbah melalui metode everyone is teacher here lebih tinggi dibanding melalui metode guided note taking.

Siswa kelas eksperimen I diajar melalui metode everyone is teacher here dan kelas eksperimen II diajar melalui metode guided note taking. Pada akhir pembelajaran dilakukan post-tes untuk mengetahui ada atau tidaknya perbedaan motivasi belajar pada kedua kelas eksperimen tersebut.

Penelitian penggunaan metode everyone is teacher here dan guided note taking terhadap motivasi belajar siswa, tujuan utamanya adalah untuk mengetahui perbedaan dari kedua metode tersebut mana yang lebih menarik dan menjadikan siswa lebih aktif dalam proses pembelajaran sehingga dapat meningkatkan motivasi 
belajar siswa. Motivasi belajar sendiri memiliki dampak terhadap perilaku siswa sehingga mampu meningkatkan semangat dan ketekunan belajar siswa (Widoyoko, 2017).

Berdasaran hasil penelitian dapat disimpulkan bahwa motivasi belajar siswa yang disampaikan melalui metode Everyone is teacher here lebih tinggi dari motivasi belajar siswa dengan metode guided note taking di MAN 1 Semarang pada materi perubahan lingkungan dan daur ulang limbah. Hal tersebut dapat menunjukkan bahwa tidak semua metode pembelajaran cocok dengan semua materi pelajaran mungkin hanya materi tertentu saja.

Kelebihan dari metode everyone is teacher here adalah mampu melatih siswa dapat berperan menjadi guru dihadapan teman-temannya ketika diskusi dalam pebelajaran sehingga dapat meningkatkan kemampuan mengungkapkan pendapat, mampu mengembangkan kemampuan berfikir sendiri sehingga dapat memecahkan masalah yang dihadapi sehingga menumbuhkan proses berfikir positif (Fitriani, 2018). Pada kelas eksperimen II yang diajar dengan metode guided note taking siswa kurang antusias ketika proses pembelajaran, karena siswa harus terfokus pada apa yang disampaikan guru agar dapat menjawab pertanyaan. Hal tersebut tidak sesuai dengan pendapat suprijono (2012) dalam bukunya yang mengemukakan bahwa metode guided note taking sebagai pendukung agar metode ceramah guru dapat menarik perhatian siswa. Namun pada kenyataannya siswa malah cenderung bosan dan tidak fokus pada apa yang disampaikan oleh guru. Sehingga pada penelitian ini motivasi belajar siswa dengan metode guided note taking lebih rendah dibanding metode everyone is teacher here.

Selain berdasarkan pendapat ahli, peneliti juga didukung oleh penelitian terdahulu yang dilakukan oleh Jannah (2018) melakukan penelitian mengenai Pengaruh Strategi Pembelajaran Everyone Is Teacher Here Terhadap Kecakapan Sosial dan Berpikir Kritis Siswa Kelas XI MIA Pada Mata Pelajaran Biologi di MAN 2 Lombok Tengah Tahun Pelajaran 2017/2018. Hasilnya menunjukkan bahwa, berdasarkan analisis data, diketahui bahwa terdapat $37,1 \%$ siswa kelas eksperimen yang memiliki kecakapan sosial yang baik sedangkan pada kelas kontrol terdapat $13,3 \%$ siswa yang memiliki kecakapan sosial yang baik. Quadri (2010) melakukan penelitian mengenai perbandingan penerapan metode pembelajaran guided note taking (catatan terbimbing) dengan metode ekspositori terhadap hasil belajar siswa kelas X IPA SMA Negeri 1 Bajo Kec.Bajo Kab. Lawu. Hasilnya rata-rata hasil belajar siswa menggunakan metode ekspositori 45,44 sedangkan rata-rata hasil belajar siswa mengggunakan metode guided note taking yaitu 73,48 . Sehingga hasil penelitian menunjukkan bahwa hasil belajar siswa yang diajar melalui metode guided note taking lebih tinggi dibanding dengan hasil belajar siswa yang diajar melalui metode ekspositori.

Perbedaan penelitian tersebut dengan penelitian ini terdapat pada desain penelitian yang digunakan yaitu quasi eksperimental dan menggunakan lembar observasi dan tes. Sedangkan penelitian yang dilakukan peneliti instrumen yang digunakan adalah lembar observasi berupa angket yang diisi oleh siswa. 


\section{SIMPULAN DAN SARAN}

Motivasi belajar siswa pada materi perubahan lingkungan dan daur ulang limbah dengan penerapan metode Everyone is teacher here memiliki skor yang lebih tinggi jika dibandingkan skor motivasi belajar siswa dengan metode guided note taking. Hal tersebut dapat menunjukkan bahwa tidak semua metode pembelajaran cocok dengan semua materi pelajaran mungkin hanya materi tertentu saja.

\section{RUJUKAN}

Djamarah, Syaiful Bahri. (2008). Psikologi Belajar Edisi 2. Jakarta: Rineka Cipta Fidiyanti, H. H. N. (2017). Effect of Implementation of Cooperative Learning Model Make A Match Technique on Student Learning Motivation in Social Science Learning. International Journal Pedagogy of Social Studies, 2(1), 104. https://doi.org/10.17509/ijposs.v2i 1.8667

Firdaus, A. R. (2018). Application of Everyone is a Teacher Here Learning Model to Improve Self Confidence Students. Journal of Elementary Education, 2(2), 8795. https://doi.org/https://doi.org/10.22 460/pej.v2i2.1007

Fitriani. (2018). Pengaruh Metode Pembelajaran Everyone is Teacher Here Dengan Media Handout Terhadap Keaktifan Dan Hasil Belajar Siswa Kelas XI IPS SMAN 1 Perhentian Raja. Jurnal Pendidikan Ekonomi Akuntansi FKIP UIR, 6(1), 44-52. Jannah, Fitriyatul. (2018). Pengaruh Strategi Pembelajaran Everyone is Teacher Here Terhadap Kecakapn Sosial dan Berpikir Kritis Sisa Kelas XI MIA Pada Mata Pelajaran Biologi di MAN 2 Lombok Tengah Tahun Pelajaran 2017/2018. Skrispi. Lombok: UIN Mataram.

Lestari, karunia Eka dan Mokhamad Ridwan Yudhanegara. (2015). Penelitian Pendidikan Matematika. Jakarta: PT Refika Aditama.

Maonde, F., Bey, A., Anggo, M., Rahim, U., \& Tiya, K. (2015). The Discrepancy of Students' Mathematic Achievement through Cooperative Learning Model, and the ability in mastering Languages and Science. International Journal of Education and Research, 3(1), 141-158.

Ningsih, S. Y., \& Gustimalasari. (2018). Penggunaan Strategi Pembelajaran Aktif Everyone is a teacher Here (ETH) Terhadap Kemampuan Pemahaman Konsep Matematika Ssiwa Kelas VII. Journal of Mathematics Education and Science (MES), 4(1), 95-100.

Nugroho, A. A., Dwijayanti, I., \& Atmoko, P. Y. (2020). Pengaruh Model Pembelajaran

Berbasis Penemuan dan lingkungan Terhadap Kemampuan Pemecahan

Masalah Matematika Melalui Meta Analisis. Jurnal Program Studi Pendidikan Matematika (Aksioma), 9(1), 147-157.

Quadri, Hassul. (2010). Perbandingan Penerapan Metode Pembelajaran Guided Note

Taking (Catatan Terbimbing) dengan Metode Pembelajaran Ekspositori Terhadap Hasil Belajar Matematika Siswa Kelas XI IPA SMA Negeri Bajo Kec.Bajo Kab. Luwu. Skripsi. Makassar: UIN Alauddin.

Sugiyono. (2016). Metode Penelitian Pendidikan. Bandung: Alfabeta. 
Suprijono, Agus. (2012). Cooperative Learning Teori dan Aplikasi Paikem. Yogyakarta: Pustaka Pelajar.

Ummah, N. A., \& Budiyono. (2018). Penarapan Strategi Everyone is a Teacher Here Untuk Meningkatkan Hasil Belajar Matematika Kelas IV. Jurnal Penelitian Guru Sekolah Dasar (JPGSD), 06(03), 322-331.

Widoyoko, Eko Putro. (2012). Teknik Penyusunan Instrumen Penelitian. Yogyakarta: Pustaka Pelajar.

Zuliani, P., \& Nasir, M. (2017). Penerapan Model Pembelajaran Everyone Is A Teacher Here (ETH) untuk Meningkatkan Aktivitas dan Hasil Belajar Kimia Koloid Siswa Kelas XI IA di SMA Negeri 5 Banda Aceh, Jurnal IImiah Mahasiswa Pendidikan Kimia (JIMPK), 2(1), 65-72. 